\title{
Research on English Testing for General Academic Purposes in General Engineering Universities
}

\author{
Xixiang Ke and Xue Yang \\ Wuhan Textile University, Wuhan, China 430070 \\ 1753270552@qq.com,2296204523@qq.com
}

Keywords: EGAP testing; Academic skills; Academic literacy; Language competence

\begin{abstract}
EGAP is a vital branch of ESP whose testing is to satisfy the needs of the country and students to apply English in academic study and future career. This differs from the purpose of English for general purposes whose testing is to measure language competence alone. It is concluded that EGAP testing should aim to test students' ability in academic listening, speaking, reading, writing and translating as well as language competence. This paper emphasizes the significance and necessities of EGAP testing and explores its testing system in general engineering universities. Much research is to be done in this respect.
\end{abstract}

\section{Introduction}

The recent guidelines for College English teaching have regarded ESP as one of the main contents of college English education [1], which reveals that the orientation of college English teaching in our country began to change, English for specific purposes eventually being an indispensable part of college English education. How to measure the effectiveness of English for general academic purpose, a significant branch of ESP, becomes necessary and urgent.

College English reform is in full swing. General academic English is becoming the development of many college English teaching in China. Scholars and teachers have done much research in such aspects as textbook compiling, EGAP teaching syllabus, demand analysis of academic English, academic English curriculum establishment, teaching methods, teacher training. However, little research is concerning evaluation and testing of academic English. This paper is to analyze the different purposes of testing between English for general English purposes and academic purposes. This will start from the discussion of differences between EGP and EGAP.

\section{The Necessities of Testing System for EGAP}

Because EGP is different from EGAP in many aspects such as teaching purpose, teaching content, teaching method, teaching design etc. accordingly the way to measure students' performance should be different. EGAP aims to cultivate language competence, academic skills as well as academic literacy. Language competence is improved implicitly. Academic skills include the ability to read discipline-specific articles, listen to academic report and make notes, the ability to present research result in English in the seminar or workshop, the ability to write papers based on academic format, the ability to put forward questions, analyze questions and solve questions. Thus the ability of critical thinking and innovation are to be improved during the learning of EGAP. Academic literacy refers to the ability to do research and learn autonomously, the ability to analyze, comment on and synthesize information, the ability to do a project, the ability to avoid plagiarism and comply with universal academic standards. EGP aims merely to improve language competence. Teaching purposes differ so much that testing are supposed to differ, too.

In short, EGP testing is based on learners' language level while EGAP testing on learners' ability to apply English in academic settings and future professional settings.

EGAP testing, driven by national requirements and students' professional needs, aims to test whether language expression conforms to discipline format or not, contributing to the development of industry. However, EGP testing, driven by personal language learning [2], aims to measure 
language accuracy and fluency, contributing to teaching evaluation, which is not closely relevant to the development of industry.

Interestingly, although they differ from each other, they have something in common. Both can cultivate culture literacy and language literacy. It is explicit in EGP teaching while implicit in EGAP teaching, for culture and language are embedded in academic writing. Both can adopt the combination of formative and summative assessment. Testing content and testing ways can be different.

\section{Establishment of Testing System}

Several concepts concerning testing should be interpreted clearly before establishing testing system.

First of all, fairness should be given priority. If something is wrong with the fairness of the test, then other factors of the test, such as validity, reliability, authenticity and social value will be meaningless. Fairness of language tests and testing practices has always been a concern among test developers and test users. In the past decade educational and language assessment researchers have begun to focus directly on fairness and related matters such as test standards, test bias and equity and ethics for testing professionals[3].

Both EGP and EGAP testing involve validity and reliability. A good test means a proper combination of reliability and validity. Reliability refers to the consistency and stability of the results produced by a test. The examination result of test takers who repeats the same paper under the same conditions should be consistent. Validity means whether a test measure what it wants to measure [4]. If answers are affirmative, the test is a good one.

In addition, value is another concept that should be taken into account [5]. Whether a test measures students' academic ability is central to country's development. The result of test should conform to national requirements concerning talent cultivation. Cultivation of talents is closely related to testing systems. A valid, valuable and reliable test contributes much to cultivation of talents needed by all walks of life and our country. Nowadays, talents who can use English in their fields are in demand with the development of society and country. Some universities [6] regard academic test such as IELTS and TOEFL as a standard to enroll graduate students instead of CET six which does not enable students adapt to future study and work[7], for TOEFL and IELTS measure academic ability. This may indicate academic literacy and academic skills are becoming necessary and popular to some degree.

The content and ways of testing are to be discussed below.

First, demand analysis is necessary. The demand of profession, students and country are to be taken into account. Demands can be obtained via questionnaire and interview. With demands, the content of test can be determined.

Second, developing vocabulary of EGAP is vital for testing syllabus [8]. High frequency discipline-specific vocabulary can be collected. The vocabulary can be divided into two parts, one being core vocabulary, the other being optional vocabulary. The core vocabulary will be a part of testing syllabus. In the written test, the core vocabulary can be contained in the test.

Third, set up corpus on professional settings in specific fields [9]. Teaching group can be organized by teachers from foreign language department and teachers or experts specialized in other disciplines. Learning Group can be set up as well. There is no rich resources in general engineering universities. Students can be motivated to participate in the construction of corpora. These settings are also the content of testing.

Specifically speaking, the content of EGAP testing is not completely academic, but involves introductory material in various disciplines, namely academic encyclopedic knowledge, such as math in our life, the development of submarine, environment and pollution, computer and human, artificial intelligence, chemical and human, autism, genetically modified food, euthanasia, electronic commerce, city sculpture, light pollution and construction etc. Whatever jobs people take, they should have a wide range of interdisciplinary knowledge, which is in line with the development of interdisciplinary general education in universities. Universal academic English tests 
help general education. In a word, EGAP testing is interdisciplinary by nature [10]. Passing the test implies students have mastered necessary skills for professional study and research.

As discussed above, formative and summative assessment can be combined to assess students' performance. The tasks and activities students are expected to fulfill in learning EGAP are presented in the form of test. Testing content, according to teaching purposes, are expected to measure those abilities mentioned above.

The content of formative assessment includes daily performance, such as project presentation, research report, paper writing, literature review, questionnaire and interview. Listening and speaking ability can be measured in formative assessment. Summative assessment can be done in the form of written test. Reading comprehension, writing, analyzing ability can be tested by written test.

A case study of formative assessment is as follows.

Take unit five-Electronic Business in the textbook entitled Academic English for Business for example, in the first place, students are encouraged to search literature or items related to Ebusiness out of class, then have a brain storming in class. During discussion, students find out topics that interest them, such as the background of electronic business, the causes of electronic business, the pros and cons of electronic business, differences between entity economy and electronic business etc. Students are graded according to information offering and their ability to search literature.

Second, students can be divided into groups with five or six members in one group based upon their research interests. Each group begins to conduct respective research. Group members negotiate the division of task by themselves, such as project leader, PPT designer, data collector, data analyst, discussion recorder and report writer. Group members make research plans together, discuss research questionnaire, interview questions, research background and research method. Teacher will be the facilitator to help each group establish those.

Then each group starts to implement research plan. The materials collected are sifted through and analyzed by members together. The report writer finishes research report, which is to be modified and finalized by group members. Last, presentation in class is expected with questioning afterwards. Both teacher and students participate in the questioning. Each group modifies the report again according to suggestions of classmates and teachers.

Accordingly, the performance of each group is assessed by other groups and teacher as well. Assessment of project research can comply with the following criteria: reasonability of task division, independence of research, efficiency of team work, mobilization of member, depth and width of research report, norm of research paper. Besides, adequacy of literature collection, value of project, problem consciousness, scientific nature of research method, reasonability of theoretical framework and data processing, sufficiency of data interpretation and reasonability of conclusion are taken into account. During presentation, the logic and clarity of statement, conciseness of PPT and effectiveness of question answering are supposed to be considered. These can be the standards of assessment.

Summative assessment is made at the end of semester. Written test may include two passages for comprehension in the form of multiple choices. Another two passages can be employed for students to analyze and synthesize information. Underline some key words and ask students to paraphrase them. Lectures can be chosen to test listening comprehension in the form of blank filling and multiple choices. Terminology as items can appear in the form of cloze.

\section{Summary}

The design of EGAP testing is an urgent task that is to fulfill to ensure the effectiveness of new reform in college English education. Fairness, reliability, validity and social value are supposed to be taken into consideration for test developers. Formative assessment and summative assessment are integrated to measure learners' academic skills, academic literacy as well as language competence. The former is realized by project research, the latter by written test. 


\section{Acknowledgement}

This work was financially supported by Hubei Provincial Department of Education and Wuhan Textile University (201608014).

\section{References}

[1] Cai Jigang. Testing English for General or Specific Purposes-a Study on the Re-orientation of College English Test [J].Computer-Assisted Foreign Language Education2012 ( 146 ) : 27-32. (In Chinese)

[2] Bachman, L. F. Fundamental Considerations in Language Testing [M].Oxford: Oxford University Press, 1990.

[3] Antony John Kunnan Studies in Language Testing 9: Fairness and Validation in Language Assessment[M]. Cambridge University Press, 2000.

[4] Tong Yangfen, Chen Youlin. Influence of background knowledge on Language Testing [J]. Journal of Xi' an International Studies University 2015(4): 65-69. (In Chinese)

[5] Douglas, D. Assessing Languages for Specific Purposes [M].Cambridge: Cambridge University Press, 2000.

[6] Lado, R. Language Testing. New York: McGraw-Hill, 1961.

[7] Messick, S. Validity [A].In R. L. Linn(ed.)Educational Measurement(3rd edition) [C]. New York: Macmillan, 1989.

[8] Glenn Fulcher \& Fred Davidson. Language Testing and Assessment [M]. Routledge, 2007.

[9] Lyle F. Bachman Language Testing in Practice [M]. Oxford University Press, 1998.

[10] O'Sullivan, Barry Language Testing: Theories and Practices [M]. Palgrave MacMillan, 2011. 